Universidad de Lima

Escuela de Posgrado

Maestría en Derecho Empresarial

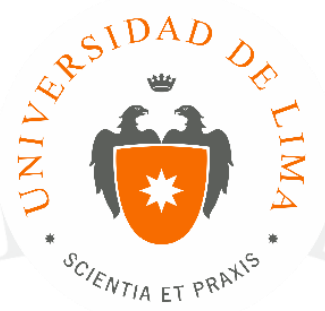

\title{
LA CADUCIDAD DE LA RESPONSABILIDAD \\ CIVIL DE LOS DIRECTORES DE UNA SOCIEDAD ANÓNIMA
}

Trabajo de investigación para optar el Grado Académico de Maestro en Derecho Empresarial

\section{Ruth Natalia Tambini Monge}

Código 20021512

$$
\text { Lima - Perú }
$$

Marzo del 2016 


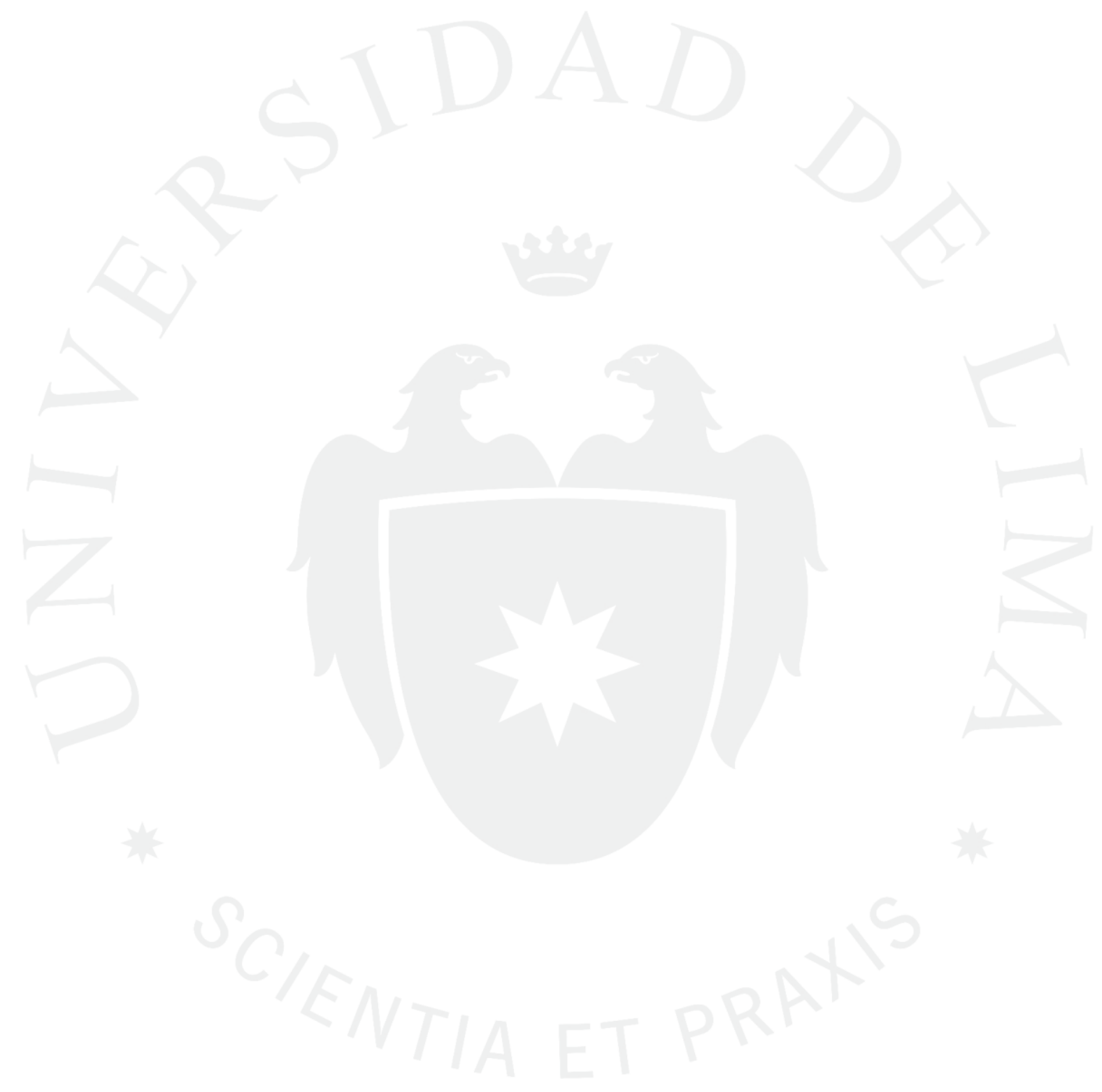




\section{LA CADUCIDAD DE LA RESPONSABILIDAD CIVIL DE LOS DIRECTORES DE UNA SOCIEDAD ANÓNIMA}




\section{TABLA DE CONTENIDO}

INTRODUCCIÓN

1

CAPÍTULO I: DIRECTORES COMO ÓRGANO DE GOBIERNO DE LA

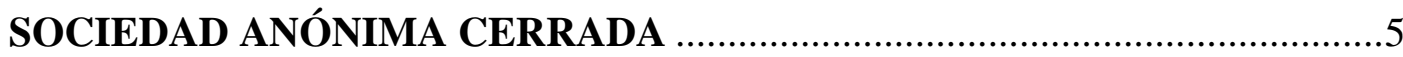

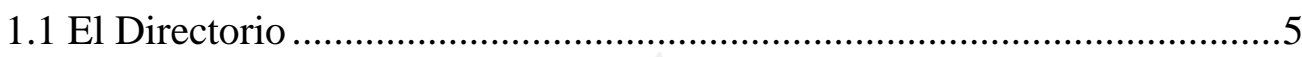

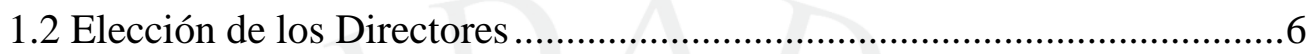

1.3 Estándar Profesional y Funciones del Directorio ......................................7

1.4 De la Responsabilidad de los Directores y Gerentes................................8

CAPÍTULO II: LA PRESCRIPCIÓN Y LA CADUCIDAD ..............................10

2.1. De La prescripción ...........................................................................10

2.1.1 La prescripción en el Derecho Civil .....................................................10

2.1.2 La Prescripción en el Derecho Administrativo Sancionador ..................11

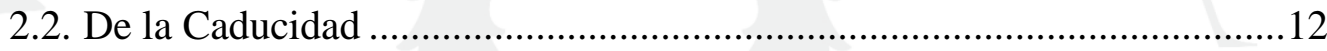

2.2.1 De la Caducidad de Responsabilidad de los Administradores................13

CAPITULO 3: ABUSO DEL DERECHO Y TIEMPO RAZONABLE .............14

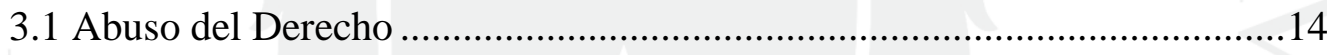

3.2 El Tiempo Razonable ...................................................................... 15

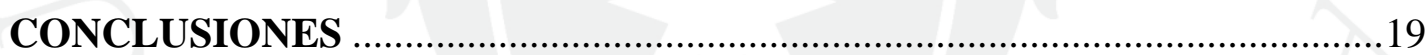

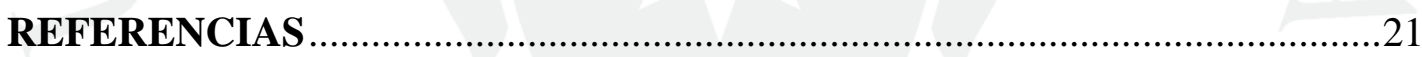




\section{INTRODUCCIÓN}

Bajo el título La caducidad de la responsabilidad civil de los directores de una sociedad anónima, abordamos una realidad societaria en que, la identificación de hechos generadores de eventual responsabilidad de Directores o Gerentes, como consecuencia de actos dolosos o negligentes del órgano de gobierno, se efectúan en lapsos posteriores al período en que los sujetos detentaron la calidad de Directores o Gerentes, lapso de vigencia en que resultó imposible que afloren evidencias o se genere un espacio de profunda y decidida investigación; inacción que como es lógico podrá exceder más de dos años, con lo cual ya ha caducado el derecho y la acción. En tal sentido, además de esgrimir la conveniencia de modificar la caducidad por la prescripción, se plantea la propuesta de que durante la vigencia de Director o Gerente del eventual responsable, no se inicia el plazo de caducidad, como corolario de ello, el inicio del plazo de caducidad se iniciara una vez aflorado las evidencias del acto doloso o negligente, generalmente con posterioridad a la remoción del Director o Gerente implicado; en consecuencia, una segunda condición radicara en que el sujeto implicado debe ser apartado del cargo de Director o Gerente, exigencia mínima que asegura una vocación de dilucidar e investigar los actos atentatorios a la persona jurídica.

Acorde a ello se desterrará la mala praxis de hacer uso abusivo de las instituciones extintivas o que dotan de seguridad jurídica, verbigracia la "caducidad", cuya instrumentalización perversa puede servir para encubrir el fraude por parte de los integrantes del órgano de gobierno de las Sociedades Anónimas, en la administración y gestión de las operaciones y negocios conducentes al objeto social previsto en su estatuto, o fuera de los mismos, lo que en la doctrina se denomina, actos ultra vires.

En torno a dichas premisas, entonces, cabría preguntarse, ¿Cuáles son los criterios funcionales para viabilizar un efectivo proceso, civil o administrativo, generado como consecuencia de actos fraudulentos de los Directores o Gerentes? ¿Cuáles son las circunstancias impeditivas para el inicio del plazo de caducidad de responsabilidad de los Directores o Gerentes de la sociedad anónima?; Al respecto, esbozamos como hipótesis que: I.- El plazo de caducidad no se inicia por obstrucción, omisiva o comisiva, de los integrantes del órgano de gobierno, directa o indirectamente; 
y II.- El plazo de caducidad no se inicia mientras detente la condición de órgano de gobierno, los eventuales responsables.

En efecto, en el ámbito de la responsabilidad societaria de los Directores, esto es, en la Ley General de Sociedades (Ley N. ${ }^{\circ}$ 26887, 1997) (en adelante, LGS), se encuentra regulado, entre otros dispositivos, en el artículo $177^{\circ}$-sobre la negligencia grave-; por otro lado, el artículo $184^{\circ}$ señala que la responsabilidad civil caduca a los dos años de la fecha de adopción del acuerdo o de la realización del acto que origino el daño; empero, si los socios, terceros o la misma sociedad, toman conocimiento del daño una vez que el Director culmino de su cargo -que puede ser varios años - para ello ya pasaron más de dos años que se produjo el daño o se celebró el acuerdo, con la consiguiente impunidad, ante la imposibilidad de acudir al ente jurisdiccional.

De esta forma, el abordaje del tema y sub temas, como lo constituye la caducidad no debe estar asociado indisolublemente al transcurrir del tiempo ontológico o natural, sino al tiempo funcional o normativo, esto es, el intervalo de tiempo en el que se dan las condiciones para un efectivo ejercicio de la acción y del derecho; postulado que debe ser aplicable antes eventuales actos fraudulentos generado por los órganos de gobierno de la sociedad anónima.

En efecto, la actividad empresarial ha cobrado mucha relevancia y complejidad en nuestro medio y de manera global, constituyendo la dirección de las empresas crucial y acentuadamente técnico, por ello se delega el órgano de gobierno y la conducción de la sociedad anónima a renombrados profesionales (Administradores o Directores), por lo que, se exige un funcional y eficaz régimen de responsabilidad, que salvaguarde a los socios, a la sociedad y a terceros.

Llegados a este punto, esperamos contribuir a la discusión y que este trabajo pueda servir para el desarrollo de otras líneas de investigación o se profundicen sus premisas. 


\section{HIPOTESIS DE TRABAJO}

Las hipótesis que se plantearon para el trabajo de investigación que me propongo realizar son las siguientes:

a) La conducta obstruccionista del Director o Gerente, omisiva o comisiva, impide el inicio del plazo de caducidad de dos años.

b) El plazo de caducidad de dos años no se inicia, mientras los eventuales responsables detenten la condición de órgano de gobierno.

c) Asumiendo un criterio funcional para la institución de la caducidad, evitaremos que se instrumentalice de cara a encubrir el fraude de los Directores y Gerentes de las Sociedades Anónimas.

Debemos optar por un tiempo funcional o normativo, caracterizado por la existencia de condiciones para un efectivo ejercicio de la acción y del derecho.

Con relación a esta hipótesis a) y b), formulamos los siguientes desagregados de estudio y análisis. Afirmamos, por ejemplo, que:

La aplicación de la caducidad, sin los matices y particularidades de la realidad societaria, desnaturalizaría y conllevaría al abuso de derecho de la institución, dado que: (1) fomentaría el incumplimiento de sus responsabilidades de actuar con la diligencia de un ordenado comerciante y un representante leal, de buena fe y con principios éticos; y (2) incumplir también sus obligaciones en agravio de la sociedad anónima, lo que se agrava si durante su permanencia como integrantes del órgano de gobierno de la persona jurídica, obstruyeron, directa o indirectamente, a que no se descubran los hechos y se frustre un efectivo ejercicio de las acciones legales o impugnaciones, dentro del plazo razonable. (3) Conllevaría a la impunidad sino no reparamos que la permanencia del Director o Gerente de la sociedad anónima, permanece como integrante del órgano de gobierno. (4) La aplicación mecánica de la "caducidad", sin las particularidades del caso, conllevaría al encubrimiento de fraude de los Directores y Gerentes, generando un manto de impunidad.

Según Jugo Oblitas (2011), en efecto, en el ámbito de la responsabilidad societaria de los Directores, esto es, en la Ley General de Sociedades, se encuentra regulado, entre otros dispositivos, en el artículo $177^{\circ}$ de la LGS -sobre dolo o negligencia grave-; por otro lado, el artículo $184^{\circ}$ de la LGS señala que la 
responsabilidad civil caduca a los dos años de la fecha de adopción del acuerdo o de la realización del acto que origino el daño; empero, si los socios, terceros o la misma sociedad, toman conocimiento del daño una vez que el director culmino de su cargo que puede ser varios años - para ello ya pasaron más de dos años que se produjo el daño o se celebró el acuerdo, con la consiguiente impunidad, ante la impunidad de acudir al ente jurisdiccional.

\section{JUSTIFICACION:}

Dotar de racionalidad y concordancia practica a la institución de la caducidad, construyendo un andamiaje de la responsabilidad civil de los directores, a partir de la actual real societaria, y que responda a los grandes cambios en el ámbito empresarial.

\section{TIPO DE INVESTIGACION:}

Se realizó un trabajo teórico-doctrinario, mediante el cual se ha dotado de un nuevo contendido a las instituciones jurídicas, se han revisado las normas que involucran a nuestra investigación, proponiendo así un plazo funcional para el ejercicio de la acción por responsabilidad civil de los Directores, coherente con la proscripción del abuso del derecho y la necesidad de dotar de racionalidad a las instituciones civil, a partir de la nueva realidad societaria. 


\section{CAPÍTULO I: DIRECTORES COMO ÓRGANO DE GOBIERNO DE LA SOCIEDAD ANÓNIMA CERRADA}

Los órganos de gobierno de las sociedades anónimas son: La Junta General de Accionistas y Los Administradores (Directorio y Gerencia). Broseta Pont y Martínez Sanz (2002), relievan que, la sociedad anónima necesita de los órganos para crear, emitir y ejecutar su voluntad, así como para concertar los actos y estipular negocios de relación con terceros a través de los cuales realiza el objeto social para cuya consecución fue constituida.

\subsection{El Directorio}

La institución del Directorio se encuentra influenciado por derecho anglosajón, y en relación a su estructura y funcionamiento, se nutre del derecho comparado, como son Francia, Italia y España donde se lo denomina como Consejo de Administración.

Hundskopf Exebio (2003), señala que, en nuestra normatividad societaria, la regulación es distinta, de la administración se encargan tanto el directorio como la gerencia, compuesto el primero por directores y el segundo por el gerente. Es así que, cuando hablamos de consejo de administración nos estamos refiriendo al directorio peruano.

Según Jugo Oblitas (2011), el directorio, es el órgano de administración que mayor influencia tiene en la administración de la sociedad, es el órgano colegiado que se encarga de la gestión y administración de la sociedad anónima. En el caso de las sociedades anónimas ordinarias y las sociedades anónimas abiertas, son parte de la administración tanto el directorio como la gerencia, conforme a lo prescrito en el artículo $152^{\circ}$ de la LGS; por otro lado, la gerencia se encuentra bajo las decisiones del directorio, efectiviza las decisiones tanto del directorio como de la junta general de accionistas. En el marco, de las sociedades anónimas cerradas, el nombramiento del directorio es facultativo, y es el gerente general quien cumple sus funciones conforme lo estipula el artículo $247^{\circ}$ de la LGS. (p. 36, 39) 
En el marco de desarrollo del presente trabajo, focalizaremos nuestra atención en el directorio, en su faceta de órgano encargado de la gestión y representación de la sociedad, así como de las amplias facultades de las que se encuentran revestidos.

En nuestro ordenamiento societario, la función de administración de una sociedad anónima, conforme a lo prescrito en el artículo $152^{\circ}$ de la Ley General de Sociedades, recae en el directorio; en efecto, dicho dispositivo establece que: "La administración de la sociedad está a cargo del directorio y de uno o más gerentes, salvo lo dispuesto en el artículo $247^{\circ}$ ".

\subsection{Elección de los Directores}

La elección de los miembros del directorio se rige por el principio de libre revocabilidad de los administradores, el cual refiere que la Junta General de Accionistas puede en cualquier momento revocar el cargo de director. Dicha remoción puede ser decidida sin expresión de causa que la motive, por ello se señala que es un caso de remoción ad nutum. La Ley General de Sociedades, señala que el número de los miembros que conforman el directorio debe ser como mínimo tres personas, ello se debe a que los acuerdos que adopta el directorio se hace por medio de la mayoría absoluta, por eso la Ley General de Sociedades estipula que, el estatuto puede señalar el mínimo y máximo de miembros de un directorio, estableciendo como mínimo el número de tres miembros. (Jugo Oblitas, 2011, p. 47)

Acorde a ello, la Ley General de Sociedades, regula la posibilidad que la Junta General de Accionistas nombre miembros suplentes o alternos, a fin de llenar el vacío que deje la ausencia o inhabilitación temporal o definitiva de los integrantes titulares, ello claro está que la Junta General de Accionistas debe definir la forma, el orden y modo de llevarse a cabo la sustitución. En cuanto a la vacancia de los directores, se debe a los siguientes motivos: 1) fallecimiento, ya que la muerte al poner fin a la persona pone fin a los cargos intuito personae que asumía; 2) renuncia, ello deviene como contrapartida de la remoción del cargo, el director puede en cualquier momento renunciar al cargo haciendo la respectiva comunicación a la sociedad; 3) remoción, como potestad única de la junta general de accionistas; 4) los impedimentos que señale la ley o el estatuto. (Jugo Oblitas, 2011, p. 47) 


\subsection{Estándar Profesional y Funciones del Directorio}

Los administradores han de desempeñar su cargo de conformidad a "la diligencia de un ordenado empresario y de un representante leal" (Ley de Sociedades Anónimas Española, Articulo $127^{\circ}$ ). Esta referencia al "empresario" quiere expresar que la diligencia que debe desplegar el administrador, en lugar de referirse al "buen padre de familia" (como modelo de diligencia empleado para el mandatario por el artículo $1719^{\circ}$ del Código Civil Español), debe tener un carácter profesional, en el sentido de hacer referencia a una persona que conoce la labor que la administración de la sociedad implica. Además, ha de desempeñar el cargo con la diligencia de un "ordenado empresario", ya que el administrador debe tener un grado de dedicación y de atención a su labor - de "orden" respecto a ella - para poder llevar adelante la administración del negocio (Sánchez Calero, 2014. p. 241).

De esta forma, los integrantes del directorio, deben observar un accionar acorde a la diligencia de un ordenado comerciante y representante leal, marco general, que es el estándar a observar de manera abstracta y general, y sirve de referente para determinar alguna responsabilidad del órgano de gobierno, en efecto, los directores no pueden soslayar dicho estándar, ya que es el marco sobre el cual deben actuar a fin de compatibilizar con el objeto social de la sociedad. Lo que se complementa con el artículo $171^{\circ}$ de la LGS, al prescribir como obligación que los directores deben de guardar reserva respecto de los negocios o información privilegiada que por ejercicio de su cargo sea encomendada a ellos, lo que cobra actualidad y relevancia una vez que han culminado con su cargo, ello a fin de custodiar los intereses de la sociedad. (Jugo Oblitas, 2011, p. 53)

Por otro lado, según Sánchez Calero (2014):

(...) a los administradores la gestión y la representación de la sociedad. La administración de la sociedad comprende la realización de un conjunto de actos, de diversa naturaleza, tendentes a la consecución del objeto social. En este sentido, resulta claro que se confiere a los administradores competencia sobre asuntos de una cierta complejidad, por lo que dicho concepto denota una noción amplia.

El órgano dedicado a la administración de la sociedad es necesario, precisamente por tener conferida la gestión y la representación de la sociedad. Su actuación es precisa, para la realización del objeto social (...) Pero al propio tiempo han de ocuparse de la 
organización de la sociedad, de su relación con los accionistas y del funcionamiento de los demás órganos de la sociedad.

\subsection{De la Responsabilidad de los Directores y Gerentes}

Toda empresa, en especial una Sociedad Anónima, tiene diseñada una estructura interna de gobierno y de administración, en dicha estructura destaca el órgano encargado de administrarlo y representarlo, para ello se requiere de un manejo eficiente de los medios de producción a fin de lograr el cumplimiento efectivo del objeto social previsto; esto se va a traslucir en la calidad de la producción y/o servicio que ofrece con el consecuente prestigio de la empresa y su consolidación en el mercado. Pero este órgano debe ser separado de los socios y del mismo capital para ello se requiere contar con personas capaces técnica y altamente profesional que se encarguen de las tareas de dirección, administración y representación de la empresa. (como citó en Villegas Lévano, 2011, p. 3)

Villegas Lévano (2011) analiza a Beaumont Callirgos (2006) en su obra Comentarios a la Ley General de Sociedades:

En este mundo moderno y globalizado con la evolución del capitalismo y la necesidad de competir y administrar eficientemente los medios de producción se origina un desplazamiento de la administración hacia personas que sin ser necesariamente los titulares del capital, tienen las condiciones profesionales suficientes para conformar un órgano interno de administración. La sociedad, para lograr su eficiencia diseña toda una estructura interna compleja en la que, a fin de conseguir la realización de su objeto social, encarga las funciones de representación, gestión y actuación empresarial a distintos órganos mediante los cuales la sociedad se expresa. Ahora bien, cabe indicar que los administradores sociales, a diferencia de los representantes, no expresan su voluntad, sino que son formadores de la voluntad de la persona jurídica. (p. 3)

Ahora bien, cuando un profesional asume la dirección o gerencia de una empresa, de hecho asume una responsabilidad de gran envergadura pues no sólo es responsable de la buena marcha del negocio sino que también se enfrenta a altos riesgos y costos por cada decisión que adopte; así el ejercicio de tales cargos va a traer consigo para los directores y gerentes de las empresas, responsabilidades de índole civil, societario, tributario, penal, entre otros. (Villegas Lévano, 2011, p. 4) 
Por otro lado, la Ley General de Sociedades con referencia al Directorio y Gerencia establece en su artículo $172^{\circ}$ que, el directorio tiene las facultades de gestión y representación legal necesarias para la administración de la sociedad dentro de su objeto, con excepción de los asuntos que la ley o el estatuto atribuyan a la junta general. Dispositivo que resulta concordante con el artículo $188^{\circ}$ de la LGS, que regula las atribuciones que tiene el gerente de una sociedad; empero, la junta general puede encargar distintas atribuciones a sus gerentes debiendo consignarse éstas en el estatuto social al momento del nombramiento o posteriormente; de lo contrario, se entenderá que tienen las atribuciones establecidas en dicho artículo cuando solamente se les designa sin hacer precisión de las atribuciones que posea. Por su parte el artículo $190^{\circ}$ de la LGS, que si bien señala la responsabilidad del gerente, también se desprenden determinadas funciones; así por ejemplo, el gerente debe controlar el uso adecuado de los activos de la sociedad, autorizar todas las operaciones que se efectúan y registrarlas correspondientemente. (Villegas Lévano, 2011, p. 11)

El primer párrafo del artículo $171^{\circ}$ de la LGS menciona que "Los directores desempeñan el cargo con la diligencia de un ordenado comerciante y de un representante leal." El desempeño, entonces, de los administradores (directores y gerentes) de una sociedad tiene que realizarse en función a tres elementos: diligencia, orden y lealtad. (Villegas Lévano, 2011, p. 17)

De esta forma, Jugo Oblitas (2011), postula que:

Los directores - como miembros de un directorio- son parte sustancial de la organización de una sociedad anónima, los mismos que son elegidos por sus cualidades profesionales y personales; y tienen dentro de sus funciones el expresar en relación a la administración y gestión, la voluntad social de la sociedad anónima que representa, para que ellos cumplan con dicho fin, la ley como el estatuto le otorga facultades amplias, siempre enmarcadas dentro del objeto social de la sociedad anónima; sin embargo, esas facultades deben de ser limitadas y ello se logra con un sistema de responsabilidad estable y seguro según sea el campo (Civil, Penal, Administrativa, etc.) (p. 93)

Un sector de la doctrina destaca que, como una alternativa de solución a la responsabilidad extracontractual de la sociedad, se debe atribuir a los administradores de dicha responsabilidad, ya que son los administradores quienes tienen el manejo de la sociedad, por tanto, está en ellos la posibilidad de reducir los daños a terceros (Bullard González, 2003). (como se citó en Jugo Oblitas, 2011, p. 93) 


\section{CAPÍTULO II: LA PRESCRIPCIÓN Y LA CADUCIDAD}

\subsection{De La prescripción}

\subsubsection{La prescripción en el Derecho Civil}

La prescripción es la figura jurídica en virtud de la cual se extingue la acción, debido al transcurso del tiempo y a la inactividad del peticionante. De esta manera, al producirse la prescripción el actor pierde su acción para exigir la declaratoria de responsabilidad y los efectos que ello implica, pero la obligación subsiste.

Cabe señalar que estamos haciendo referencia específicamente a la prescripción extintiva, cuya regulación nos remite al artículo 1989 del Código Civil: "Prescripción extintiva La prescripción extingue la acción, pero no el derecho mismo".

Hemos indicado que la prescripción tiene como característica definitoria que, se produce por el transcurso del tiempo y por la inactividad del perjudicado, y ante el cumplimiento del plazo establecido por ley para tal efecto, interregno, en el que no se ejercicio los mecanismos legales.

De esta forma, la prescripción se erige como un mecanismo de seguridad jurídica y como una sanción ante la inacción en exigir el cumplimiento de sus derechos. Ahora bien, si el efecto de la prescripción es extinguir la acción pero no el derecho, ¿Cuáles serían las consecuencias prácticas de este efecto? Ciertamente es una cuestión que se plantea con frecuencia cuando se analiza a la prescripción, pues si el acreedor pierde la acción, la interrogante que se presenta es ¿para qué le serviría mantener un derecho que no puede exigir? Pues la respuesta es sencilla, es que el deudor podría cumplir su obligación en forma voluntaria, sin necesidad que el acreedor se lo exija.

Si la prescripción tuviera como efecto extinguir no sólo la acción sino también el derecho, que es el efecto de la caducidad según veremos a continuación, el pago que efectúe el deudor voluntariamente y recibido por el acreedor, constituiría un pago 
indebido, al punto que el deudor podría solicitar la devolución del mismo; en cambio, al extinguirse sólo la acción, el acreedor aún puede recibir el pago y se considerará como un pago válido.

El plazo de prescripción se computa en días calendario y comienza a contarse desde el día en que puede ejercitarse la acción para exigir el cumplimiento de la obligación y se cumple una vez vencido el último día del plazo fijado. El Código Civil dispone las situaciones en las cuales el cómputo del plazo prescriptorio debe suspenderse o interrumpirse. La suspensión implica que el cómputo debe paralizarse y se reanudará una vez que haya desaparecido la causal de suspensión, volviendo a computarse considerando los días ya transcurridos con anterioridad a la suspensión.

En cambio, la interrupción implica que al producirse la causal de interrupción el plazo de prescripción debe dejar de computarse y al desaparecer la causal de interrupción el plazo debe computarse nuevamente, sin considerar los días transcurridos antes de la interrupción.

\subsubsection{La Prescripción en el Derecho Administrativo Sancionador}

El artículo $229^{\circ}$, inciso 1 , de la Ley $\mathrm{N}^{\circ}$ 27444, Ley de Procedimiento Administrativo General, prescribe que: "Las disposiciones del presente Capitulo disciplinan la facultad que se atribuye a cualquiera de las entidades para establecer infracciones administrativas y las consecuentes sanciones del administrado", de esta forma, dicha normatividad, se erige como el punto orientador del sistema represivo administrativo, dado que regula la facultad de establecer infracciones administrativas y sus sanciones; en consecuencia al Procedimiento Administrativo Sancionador Disciplinario estipula la observancia de garantías y principios.

En la regulación de la Ley de Procedimiento Administrativo General, modificado por Decreto Legislativo $\mathrm{N}^{\circ} 1029$, se regula la figura de prescripción de la acción administrativa en el artículo 233.1, que estipula que:

La facultad de la autoridad para determinar la existencia de infracciones administrativa prescribe en el plazo que establece las leyes especiales, sin perjuicio de los plazos para la prescripción de las demás responsabilidades que la infracción pudiera ameritar. En caso de no estar determinado, prescribirá en 
cuatro años computados a partir de la fecha en que se cometió la infracción o desde que cesó, si fuera una acción continuada.

La Ley de Procedimientos Administrativo General, establece que:

233.2 EI cómputo del plazo de prescripción de la facultad para determinar la existencia de infracciones comenzará a partir del día en que la infracción se hubiera cometido o desde que cesó, si fuera una acción continuada. EI cómputo del plazo de prescripción sólo se suspende con la iniciación del procedimiento sancionador a través de la notificación al administrado de los hechos constitutivos de infracción que les sean imputados a título de cargo, de acuerdo a lo establecido en el artículo 235, inciso 3 de esta Ley. Dicho cómputo deberá reanudarse inmediatamente si el trámite del procedimiento sancionador se mantuviera paralizado por más de veinticinco (25) días hábiles, por causa no imputable al administrado.

Marco normativo que se complementa con lo establecido en el artículo $16^{\circ}$ de la Ley de Procedimiento Administrativo General (Ley 27444, 2001), al puntualizar que: "el acto administrativo es eficaz a partir de que la notificación legalmente realizada produce sus efectos"

Solamente de esta manera se puede afirmar que el acto trasciende del ámbito meramente interno del emisor hacia el resto de personas circundantes.

\subsection{De la Caducidad}

El Artículo 2002 ${ }^{\circ}$ del Código Civil señala lo siguiente: "La Caducidad extingue en derecho y la acción correspondiente".

La caducidad, a diferencia de la prescripción, sí extingue el derecho y no solamente a la acción. Por lo tanto, el acreedor, por efecto de la caducidad, pierde su derecho y no puede recibir la prestación debida aun cuando el deudor desee ejecutarla voluntariamente, pues se consideraría como un pago indebido.

Los plazos de caducidad deben ser establecidos por ley, no se pueden establecer ni modificar por pacto entre las partes ni tampoco pueden aplicarse en forma supletoria. 
A diferencia de la prescripción, el cómputo del plazo de caducidad no se ve afectado por causales de suspensión o interrupción, salvo por la causal de suspensión prevista en el inciso 8 del artículo $1994^{\circ}$, referida a la imposibilidad de reclamar el derecho ante un tribunal peruano. El cómputo del plazo de caducidad se efectúa en días calendario y se vence el último día señalado, aun cuando tal día sea considerado inhábil.

La caducidad se diferencia también de la prescripción en la medida que la caducidad sí puede ser aplicada de oficio por el juez, sin que sea necesario que la parte interesada la invoque.

\subsubsection{De la Caducidad de Responsabilidad de los Administradores}

Enumeramos a continuación, los dispositivos de la LGS que se refieren a la caducidad de la Responsabilidad:

- Artículo $184^{\circ}$.- Caducidad de la Responsabilidad (Civil de Directores de una S.A.). (Conocimiento);

- Artículo $197^{\circ}$.- Caducidad de la Responsabilidad Civil de Gerentes de una S.A. (Conocimiento);

En efecto, el Artículo. 184․ - Caducidad de la Responsabilidad (Civil de los Directores de una Sociedad Anónima) "La responsabilidad civil de los directores caduca a los dos años de la fecha de adopción del acuerdo o de la de realización del acto que originó el daño, sin perjuicio de la responsabilidad penal”.

De esta forma, se tiene como premisa abstracta, que ella caduca a los dos años de la fecha de adopción del acuerdo o de la de realización del acto que originó el daño.

En consecuencia, deviene en gravitante el conocimiento del acto desleal o gravemente negligente de Directores de una Sociedad Anónima, lo que conforme hemos argumentado, existen altas probabilidades de no identificación mientras el Director cuestionado permanezca como órgano de gobierno de la Sociedad Anónima. 


\section{CAPITULO 3: ABUSO DEL DERECHO Y TIEMPO RAZONABLE}

\subsection{Abuso del Derecho}

El abuso de derecho no es una figura exclusiva del ámbito civil, dado que tiene alcance constitucional, conforme lo establece el artículo $103^{\circ}$ la Constitución de 1993 y en el artículo $685^{\circ}$ en el Código Procesal Civil. Respecto a la regulación dentro de la Constitución, Rubio (1997) señala que la incorporación del abuso del derecho a la Constitución de 1993 hace suponer, a diferencia de lo que ocurría antes de la aprobación del citado texto, que el abuso del derecho afecta los derechos constitucionales. De esta forma, el abuso de derecho al ser una figura de alcance constitucional y transversal al ordenamiento jurídico peruano, resulta aplicable al Derecho Societario.

La proscripción genérica, que tiene como punto de partida la figura del abuso del derecho, es categórica desde el análisis constitucional: la Constitución no ampara el abuso del derecho, afirmación que se encuentra en el párrafo final del artículo 103 de la Constitución. La figura del abuso del derecho, así como la del fraude de ley (la prohibición de ambas) tienen la propiedad de lograr combatir el formalismo que sirve de cubierta para transgredir el orden jurídico constitucional. Mientras que en el abuso del derecho se presenta un conflicto entre, por un lado, las reglas que confieren atributos al titular de un derecho subjetivo, y por otro, los principios que sirven de razones últimas para su ejercicio; el fraude de ley es la contraposición entre una regla que confiere un poder y un principio, que como tal, es de cumplimiento imperativo.

Por lo que, frente a ambos supuestos, no basta que una conducta sea compatible con una regla de derecho, sino que se exige que dicha conducta no contravenga un principio. Resaltando la preeminencia de los principios, la Constitución niega validez a todo acto contrario a su contenido principista, pese a que encuentre sustento prima facie en una regla.

(Sentencia del Tribunal Constitucional 05859-2009-AA, citado en Recurso de 
Reconsideración contra resolución de tacha (Convocatoria $\mathrm{N}^{\circ}$ 002-2010-CNM para Magistrados Supremos)

\subsection{EI Tiempo Razonable}

La razonabilidad de contar con un proceso para un efectivo ejercicio del derecho, no es de exclusiva observancia para el proceso penal, sino de alcance para todo el ordenamiento jurídico; así la Corte Interamericana de Derechos Humanos en la sentencia del Caso Valle Jaramillo y otros vs. Colombia (2008), destacó en el numeral 154 que: "el derecho de acceso a la justicia implica que la solución de la controversia se produzca en tiempo razonable, ya que una demora prolongada puede llegar a constituir, por sí misma, una violación de las garantías judiciales” (p. 48).

Y es que la naturaleza y características propias del Estado Constitucional, así como las obligaciones internacionales asumidas por el Estado en materia de derechos humanos, exigen la necesidad insoslayable de que la justicia sea impartida dentro de un plazo razonable y sin dilaciones indebidas o demoras injustificadas. (Sentencia del Tribunal Constitucional EXP. N..$^{\circ}$ 05350-2009-PHC/TC)

En el expediente No 0006-2003-AI/TC. Sentencia del 1 de diciembre de 2003. Fundamento 9 se sostiene que:

La razonabilidad es un criterio íntimamente vinculado a la justicia y está en la esencia misma del Estado constitucional de derecho. Se expresa como un mecanismo de control o interdicción de la arbitrariedad en el uso de las facultades discrecionales, exigiendo que las decisiones que se tomen en ese contexto respondan a criterios de racionalidad y que no sean arbitrarias. Esto "implica encontrar justificación lógica en los hechos, conductas y circunstancias que motivan todo acto discrecional de los poderes públicos". Aunque no explícitamente, al reconocer en los artículos $3^{\circ}$ y $43^{\circ}$ de la Constitución, el Estado social y democrático de Derecho, se ha incorporado el principio de interdicción o prohibición de todo poder ejercido en forma arbitraria e injusta. Este principio tiene un doble significado: (i) en un sentido clásico y genérico, la arbitrariedad aparece como el reverso de la justicia y el derecho; (ii) en un sentido moderno y concreto, la arbitrariedad aparece como lo carente de fundamentación objetiva, lo incongruente y contradictorio con la realidad que ha de servir de base a toda decisión. Es decir, como aquello desprendido o ajeno a toda razón de explicarlo. 
En este sentido, el análisis de la razonabilidad de una medida implica determinar si se ha dado:

a. La elección adecuada de las normas aplicables al caso y su correcta interpretación, tomando en cuenta no sólo una ley particular, sino el ordenamiento jurídico en su conjunto.

b. La comprensión objetiva y razonable de los hechos que rodean al caso, que implica no sólo una contemplación en "abstracto" de los hechos, sino su observación en directa relación con sus protagonistas, pues sólo así un "hecho" resultará menos o más tolerable, confrontándolo con los “antecedentes del servidor", como ordena la ley en este caso.

c. Una vez establecida la necesidad de la medida de sanción, porque así lo ordena la ley correctamente interpretada en relación a los hechos del caso que han sido conocidos y valorados en su integridad, entonces el tercer elemento a tener en cuenta es que la medida adoptada sea la más idónea y de menor afectación posible a los derechos de los implicados en el caso.

A modo de casuística en la Corte Suprema se discutió la necesidad de establecer si el plazo para impugnar judicialmente el acuerdo de expulsión debe computarse desde la fecha del acuerdo tomado o desde la fecha en que la impugnante tomo conocimiento del acuerdo. El artículo $92^{\circ}$ del Código Civil otorga a todo asociado el derecho a impugnar judicialmente los acuerdos que violen las disposiciones legales o estatutarias, estableciendo en su segundo párrafo, un plazo no mayor a sesenta días, contados a partir de la fecha del acuerdo, plazo que conforme a su naturaleza es de caducidad que lo fija la ley sin admitir pacto en contrario, como lo establece el artículo $2004^{\circ}$ del Código Civil: Examinado el texto y la ratio legis del inciso $8^{\circ}$ del artículo 1994 y el artículo 2005 del Código Civil, estando sustentada la sentencia impugnada en que las accionantes tomaron conocimiento de lo acordado en la citada asamblea, se determina que dichos preceptos referidos a la suspensión de la prescripción mientras sea imposible reclamar el derecho ante tribunal peruano y el carácter no interrumpible de la caducidad salvo lo dispuesto en las normas antes glosada.

En efecto, se argumentaron y ponderaron lo siguiente:

- PRIMER.- La impugnante, como sustento de su recurso, sostiene que " el plazo para impugnar judicialmente el acuerdo de expulsión debe computarse a partir de la fecha en que tomó conocimiento del referido acuerdo, no debiendo computarse desde la 
fecha del mismo; precisando que la norma de derecho aplicable al presente caso es el inciso $8^{\circ}$ del artículo 1994 del Código Civil, concordante con el artículo 2005 del mismo cuerpo normativo. El inciso 80 del artículo $1994^{\circ}$ del Código Civil de la suspensión de la prescripción mientras sea imposible reclamar el derecho ante un tribunal peruano y el artículo $2005^{\circ}$ del mismo Código se refiere al carácter no interrumpible de la caducidad, que no admite interrupción ni suspensión, salvo el caso previsto en el artículo 1994 inciso $8^{\circ}$.

- SEGUNDO.- En el presente proceso, el tema central de la controversia radica en establecer si el plazo para impugnar judicialmente el acuerdo de expulsión debe computarse desde la fecha del acuerdo tomado el veinticinco de julio de mil novecientos noventa y nueve o desde la fecha en que la recurrente tomó conocimiento del acuerdo.

- TERCERO.- La sentencia impugnada se sustenta en que las accionantes tomaron conocimiento de lo acordado en la asamblea realizada el veinticinco de julio de mil novecientos noventa y nueve, en la que se decidió su expulsión como miembro de la asociación demandada y no obstante ello dejaron transcurrir el plazo establecido por el artículo $92^{\circ}$ del Código Civil, que en su párrafo segundo concede un plazo no mayor de sesenta días a partir de la fecha del acuerdo para su impugnación judicial, habiéndose realizado el cómputo desde el veinticinco de julio de mil novecientos noventa y nueve en que se tomó el acuerdo y no como la recurrente pretende que se compute desde la fecha en que le notificaron vía notarial su expulsión el día nueve de octubre de mil novecientos noventa y nueve, por lo que a la fecha en que se presentó la demanda, el siete de diciembre de mil novecientos noventa y nueve, ya había operado la caducidad.

- CUARTO.- En tal sentido, debe establecerse si con la aplicación de las normas sustantivas citadas, que se dice no han sido aplicadas en la resolución impugnada, cambiaría el sentido de la decisión contenida en la sentencia de vista o no. El artículo $92^{\circ}$ del Código Civil otorga a todo asociado el derecho a impugnar judicialmente los acuerdos que violen las disposiciones legales o estatutarias, estableciendo en su segundo párrafo, un plazo no mayor a sesenta días, contados a partir de la fecha del acuerdo, plazo que conforme a su naturaleza es de caducidad que lo fija la ley sin admitir pacto contrario, como lo establece el artículo 2004 del Código Civil.

- QUINTO.- Examinado el texto y la ratio legis del inciso 80 del artículo $1994^{\circ}$ y el artículo $2005^{\circ}$ del Código Civil, se llega a la concluyente determinación que dichos preceptos se refieren a la suspensión de la prescripción mientras sea imposible reclamar el derecho ante un tribunal peruano y el carácter no interrumpible de la 
caducidad que no admite interrupción ni suspensión salvo el caso previsto en el artículo 1994 inciso 80 del Código citado, hecho que no se configura en el caso de autos conforme ha quedado establecido en la impugnada. De donde se concluye que la aplicación de las normas invocadas no cambiarían el sentido de la decisión.” 


\section{CONCLUSIONES}

- En el ámbito de la responsabilidad societaria de los Directores, esto es, en la Ley General de Sociedades, se encuentra regulado, entre otros dispositivos, en el artículo $177^{\circ}$ de la LGS -sobre la negligencia grave-; por otro lado, el artículo $184^{\circ}$ de la LGS señala que la responsabilidad civil caduca a los dos años de la fecha de adopción del acuerdo o de la realización del acto que origino el daño; empero, si los socios, terceros o la misma sociedad, toman conocimiento del daño una vez que el Director culmino o fue removido del cargo -que pueden ser varios años - para ello ya pasaron más de dos años que se produjo el daño o se celebró el acuerdo, con la consiguiente impunidad, ante la imposibilidad de acudir al ente jurisdiccional.

- El régimen de la caducidad de la responsabilidad civil de los directores de una sociedad anónima debe ser flexible y responder a la realidad societaria, excluyéndose todo obstáculo ex profesamente asumido, para que los ex directores respondan ante las autoridades judiciales, antes bien, la responsabilidad civil debe erigirse como institución funcional para afrontar la materia mercantil. Por ello, proponemos que, toda forma de conducta obstruccionista del Director o Gerente, omisiva o comisiva, impida el inicio del plazo de caducidad de dos años.

- Acorde a ello, el plazo de caducidad de dos años no se inicia, mientras los eventuales responsables detenten la condición de órgano de gobierno.

- En materia de caducidad debemos asumir un criterio funcional para dicha institución, evitando con ello, que se instrumentalice de cara a encubrir el fraude de los Directores de las Sociedades Anónimas; efectivamente, debemos optar por un tiempo funcional o normativo, caracterizado por la existencia de condiciones para un efectivo ejercicio de la acción y del derecho.

- La aplicación de la caducidad, sin los matices y particularidades de la realidad societaria, desnaturalizaría y conllevaría al abuso de derecho de la institución, dado que: (1) fomentaría el incumplimiento de sus responsabilidades de actuar con la diligencia de un ordenado comerciante y un representante leal, de buena fe y con principios éticos; y (2) incumplir también sus obligaciones en agravio de la sociedad anónima, lo que se agrava si durante su permanencia como integrantes del órgano de 
gobierno de la persona jurídica, obstruyeron, directa o indirectamente, a que no se descubren los hechos y se frustre un efectista ejercicio de las acciones legales o impugnaciones, dentro del plazo razonable. (3) Conllevaría a la impunidad sino no reparamos que la permanencia del director o gerente de la sociedad anónima, permanece como integrante del órgano de gobierno. (4) La aplicación mecánica de la "caducidad", sin las particularidades del caso, conllevaría al encubrimiento de fraude de los Directores y Gerentes, generando un manto de impunidad.

- Nuestra propuesta, apunta a un plazo razonable de la caducidad, de modo tal que la eventual demora, retraso o conducta obstruccionista de los directores, detentadores efectivos de tales roles, debe abordarse desde la óptica del no inicio del plazo de caducidad, de modo tal, que, ante dichas eventualidades, no pueda computarse hasta constatarse objetivamente, por ejemplo, la viabilidad de ejercer las acciones legales como consecuencia de actos o efectos generadores de responsabilidad. Lo que tiene cierto soporte legal, al estipular el Código Civil, como una causal de suspensión, entre las personas jurídicas y sus administradores, mientras éstos continúen en el ejercicio del cargo; más aún, si en la actualidad, por lo técnico y alta especialización los directores de una sociedad anónima, detenta un poder e influencia dentro de la sociedad que dirigen, lo que exige un sistema judicial que responsa a dicha realidad; una posición contraria vulneraria el derecho de acción que tienen tanto la persona jurídica, los socios o terceros perjudicados. 


\section{REFERENCIAS}

Beaumont Callirgos, R. (2006). Comentarios a la Ley General de Sociedades (6. ${ }^{\mathrm{a}}$ ed.). Lima: Gaceta Jurídica.

Broseta Pont, M. y Martínez Sanz, F. (2003), Manual de derecho mercantil (11. a ed.) Madrid: Tecnos.

Bullard González, A. (2003). Derecho y economía: el análisis económico de las instituciones legales. Lima: Palestra.

Caso Valle Jaramillo y otros vs. Colombia. (27 de noviembre del 2008). Corte Interamericana de Derechos Humanos. Recuperado de http://www.corteidh.or.cr/docs/casos/articulos/seriec_192_esp.pdf

EXP. N. ${ }^{\circ}$ 05350-2009-PHC/TC (10 de Agosto del 2010) Recurso de agravio constitucional interpuesto por don José Humberto Orrego Sánchez contra la sentencia expedida por la Cuarta Sala Penal para Procesos con Reos en Cárcel de la Corte Superior de Justicia de Lima. Recuperado de: http://www.tc.gob.pe/jurisprudencia/2010/05350-2009-HC.html

EXP. N. ${ }^{\circ}$ 05859-2009-PA/TC. (22 de junio del 2010). Recurso de agravio constitucional interpuesto por doña Luzmila Andrea Puma Quispe contra la sentencia expedida por la Primera Sala Civil de la Corte Superior de Justicia de Arequipa. Recuperado de: http://www.tc.gob.pe/jurisprudencia/2010/05859$\underline{\text { 2009-AA.html }}$

EXP. N. ${ }^{\circ}$ 00535-2009-PA/TC (5 de febrero del 2009). Recurso de agravio constitucional interpuesto por don Rodolfo Luis Oroya Gallo contra la resolución de la Sexta Sala Civil de la Corte Superior de Justicia de Lima. Recuperado de: http://www.tc.gob.pe/jurisprudencia/2009/00535-2009-AA.html

Hundskopf Exebio, O. (2003). El directorio de las sociedades anónimas. En Instituto Peruano de Derecho Mercantil (Ed.), Tratado de Derecho Mercantil (T. 1, pp. 581-620. Lima: Gaceta Jurídica.

Jugo Oblitas, A. J. (2011). La responsabilidad civil de los directores de las sociedades anónimas en el Perú. (tesis para optar el título de abogada). UNMSM.

Ley N. ${ }^{\circ}$ 26887, Ley General de Sociedades. (1997). Recuperado del Sistema Peruano de Información Jurídica: http://spij.minjus.gob.pe/spij.html

Ley N. ${ }^{\circ}$ 27444, Ley de Procedimiento Administrativo General. (2001). Recuperado del Sistema Peruano de Información Jurídica: http://spij.minjus.gob.pe/spij.html

Rubio, M. (1997). El abuso del derecho en el Perú. Revista de Derecho Privado y Comunitario, (16), 193-207. 
Sánchez-Calero Guilarte, J. (15 de abril del 2014). La delimitación del deber de diligencia de los administradores [post en un blog]. Recuperado de:

http://jsanchezcalero.com/la-delimitacion-del-deber-de-diligencia-de-losadministradores/

Sentencia del Tribunal Constitucional 05859-2009-AA, citado en Recurso de Reconsideración contra resolución de tacha (Convocatoria $\mathrm{N}^{\circ}$ 002-2010-CNM para Magistrados Supremos. Recuperado de:

http://www.justiciaviva.org.pe/webpanel/doc int/doc20012011-162750.pdf

Villegas Lévano, C. M. (2011). Responsabilidad de los directores y gerentes de las empresas frente a la Administración Tributaria. Revista Peruana de Derecho Tributario. 5 (16). Lima 


\section{BIBLIOGRAFÍA}

Atienza, M. y Ruiz Manero, J. (2006). Ilícitos atípicos (2a. Ed.), España: Trotta.

Beaumont Callirgos, R. (2004), La caducidad de instituciones y actos, derechos y obligaciones en la Ley General de Sociedades: plazos y procesos, propuestas de reforma (Tesis para optar el grado académico de Doctor en Derecho y Ciencia Política). Universidad Nacional Mayor de San Marcos.

Elías Laroza, E. (1999). Derecho societario peruano: la Ley General de Sociedades del Perú. Lima: Normas Legales.

Flores Polo, P. (1998). Comentarios a la Ley General de Sociedades. Lima: Cámara de Comercio de Lima.

Garrigues, J. (1987), Curso de derecho mercantil, (T. 2). Bogotá: Temis.

Hundskopf Exebio, O. (2012). Manual de derecho societario. (2. ${ }^{\text {a }}$ ed.). Lima: Gaceta Jurídica.

León Barandiaran, J. (1938). Comentarios al Código Civil peruano. (T. 1). Lima: Universidad Nacional Mayor de San Marcos.

Montoya Manfredi, U. (1967). Comentarios a la Ley de Sociedades Mercantiles. Lima: Universidad Nacional Mayor de San Marcos.

Morón Urbina, J.C. (2001). Comentarios a la Ley de Procedimientos Administrativos General. Lima: Gaceta Jurídica. 